\title{
Labour and delivery ward register data availability, quality, and utility - Every Newborn - birth indicators research tracking in hospitals (EN-BIRTH) study baseline analysis in three countries
}

Louise Tina Day ${ }^{1 *+}$, Georgia R. Gore-Langton ${ }^{1+} \mathbb{D}$, Ahmed Ehsanur Rahman², Omkar Basnet ${ }^{3}$, Josephine Shabani ${ }^{4}$, Tazeen Tahsina², Asmita Poudel ${ }^{3}$, Kizito Shirima ${ }^{4}$, Shafiqul Ameen², Ashish K.C. ${ }^{5}$, Nahya Salim, ${ }^{4,6}$, Sojib Bin Zaman², Donat Shamba ${ }^{4}$, Hannah Blencowe ${ }^{1}$, Harriet Ruysen', Shams El Arifeen², Dorothy Boggs ${ }^{1}$ (D, Vladimir S. Gordeev ${ }^{1,7}$, Qazi Sadeq-ur Rahman ${ }^{2}$, Tanvir Hossain ${ }^{2}$, Elisha Joshi ${ }^{8}$, Sabu Thapa $^{3}$, Rajendra Prasad Poudel ${ }^{9}$, Durga Poudel ${ }^{9}$, Priyanka Chaudhary ${ }^{3}$, Rabina Karki ${ }^{3}$, Bibek Chitrakar ${ }^{3}$, Namala Mkopi $^{6,10}$, Anna Wisiko ${ }^{4}$, Alodear Patrick Kitende ${ }^{4}$, Marystella Revocatus Shirati ${ }^{4}$, Christostomus Chingalo ${ }^{4}$, Amina Omari Semhando ${ }^{10}$, Cleopatra Mtei ${ }^{10}$, Victoria Mwenisongole ${ }^{11}$, John Mathias Bakuza ${ }^{4}$, Japhet Kombo ${ }^{4}$, Godfrey Mbaruku ${ }^{4 \wedge}$ and Joy E. Lawn ${ }^{1}$

\footnotetext{
Abstract

Background: Countries with the highest burden of maternal and newborn deaths and stillbirths often have little information on these deaths. Since over $81 \%$ of births worldwide now occur in facilities, using routine facility data could reduce this data gap. We assessed the availability, quality, and utility of routine labour and delivery ward register data in five hospitals in Bangladesh, Nepal, and Tanzania. This paper forms the baseline register assessment for the Every Newborn-Birth Indicators Research Tracking in Hospitals (EN-BIRTH) study.

Methods: We extracted 21 data elements from routine hospital labour ward registers, useful to calculate selected maternal and newborn health $(\mathrm{MNH})$ indicators. The study sites were five public hospitals during a one-year period (2016-17). We measured 1) availability: completeness of data elements by register design, 2) data quality: implausibility, internal consistency, and heaping of birthweight and explored 3) utility by calculating selected $\mathrm{MNH}$ indicators using the available data.

(Continued on next page)
}

\footnotetext{
* Correspondence: louise-tina.day@Ishtm.ac.uk

†Louise Tina Day and Georgia R. Gore-Langton are joint co-authors.

Godfrey Mbaruku is deceased.

${ }^{1}$ Maternal, Adolescent, Reproductive \& Child Health (MARCH) Centre, London

School of Hygiene and Tropical Medicine, London, UK

Full list of author information is available at the end of the article
}

\section{$\triangle B M C$}

(c) The Author(s). 2020 Open Access This article is licensed under a Creative Commons Attribution 4.0 International License, which permits use, sharing, adaptation, distribution and reproduction in any medium or format, as long as you give appropriate credit to the original author(s) and the source, provide a link to the Creative Commons licence, and indicate if changes were made. The images or other third party material in this article are included in the article's Creative Commons licence, unless indicated otherwise in a credit line to the material. If material is not included in the article's Creative Commons licence and your intended use is not permitted by statutory regulation or exceeds the permitted use, you will need to obtain permission directly from the copyright holder. To view a copy of this licence, visit http://creativecommons.org/licenses/by/4.0/ The Creative Commons Public Domain Dedication waiver (http://creativecommons.org/publicdomain/zero/1.0/) applies to the data made available in this article, unless otherwise stated in a credit line to the data. 
(Continued from previous page)

Results: Data were extracted for 20,075 births. Register design was different between the five hospitals with 10-17 of the 21 selected $\mathrm{MNH}$ data elements available. More data were available for health outcomes than interventions. Nearly all available data elements were $>95 \%$ complete in four of the five hospitals and implausible values were rare. Data elements captured in specific columns were $85.2 \%$ highly complete compared to $25.0 \%$ captured in nonspecific columns. Birthweight data were less complete for stillbirths than live births at two hospitals, and significant heaping was found in all sites, especially at $2500 \mathrm{~g}$ and $3000 \mathrm{~g}$. All five hospitals recorded count data required to calculate impact indicators including; stillbirth rate, low birthweight rate, Caesarean section rate, and mortality rates.

Conclusions: Data needed to calculate MNH indicators are mostly available and highly complete in EN-BIRTH study hospital routine labour ward registers in Bangladesh, Nepal and Tanzania. Register designs need to include interventions for coverage measurement. There is potential to improve data quality if Health Management Information Systems utilization with feedback loops can be strengthened. Routine health facility data could contribute to reduce the coverage and impact data gap around the time of birth.

Keywords: Maternal, Newborn, Stillbirth, Registers, Birth, Hospital, Routine Health Management Information Systems, Measurement, Indicators

\section{Background}

Improving quality of care at birth could save an estimated 3 million lives per year [1,2]. To drive progress, accurate data are essential, however, the majority of deaths around the time of birth occur in settings with the least information on these deaths, the "inverse data law" [3]. Improving impact and coverage data for action is central to the Sustainable Development Goal (SDG) aspiration of "no-one left behind" [4], the United $\mathrm{Na}$ tion's Global Strategy for Women's Children's and Adolescents' Health [5], and The Every Newborn Action Plan (ENAP). One of five ENAP strategic objectives is to transform metrics and use of data to improve outcomes and track progress towards ending preventable maternal and newborn deaths, including stillbirths [6].

Labour and Delivery (L\&D) ward registers are routinely completed by facility health workers and used to track ward admissions and discharges in a parallel system to patient case notes. Birth outcomes, care and interventions for women and babies are also often documented in these registers. However, concerns of poor register data quality in low- and middle- income counties (LMIC), have reduced confidence in full utilization of this data source in Health Management Information Systems (HMIS). As global facility births increase, currently $>81 \%$, [7], it is important to reassess the availability and quality of this routine data to help address the current data gap around the time of birth.

Research assessing labour ward register data in LMICs provides some explanation for the scepticism surrounding programmatic use of this source. Maternal and newborn health $(\mathrm{MNH})$ data elements were not consistently available in facility registers in 24 high burden countries [8]. In a rural primary health care context in north eastern Nigeria health workers documented in labour ward registers most completely for birthweight (99\%) and woman's age at delivery (97\%); documentation was less complete for the composite indicator essential newborn care (82\%) and preterm birth (77\%) [9]. In two rural Kenyan hospitals, entire labour ward registers were missing for months, and when present many data elements were less than $80 \%$ complete; the proportion of data legible/correctly coded/appropriate/recognized ranged from 29 to $100 \%$ [10]. In one Ethiopian hospital, among the $20 \%$ of births missing from the labour ward register, 91\% had received a clinical intervention, thus the register both underestimated total births and interventions [11]. However, the picture is not wholly negative and routine data can be improved. Data quality improvement efforts across 20 L\&D wards in South Africa, including data collection training and monthly data reviews, demonstrated increased completeness from 26 to 64\%, and accuracy from 37 to $65 \%$ [12]. In Rwanda, health system strengthening measures including performance review feedback activities, mentoring, and enhanced supervision led to increased value and ownership of data among health workers [13]. In Zanzibar, quarterly data use workshops with active engagement of data users, grew and improved the HMIS, enhancing staff capacity for information use, presentation and analysis for decision making [14].

The Every Newborn-Birth Indicators Research Tracking in Hospitals (EN-BIRTH) study aimed to assess the validity of selected newborn and maternal health care interventions indicators (coverage, content/quality, and/or safety) in hospitals [6] (Fig. 1). Our assessment of existing routine registers in EN-BIRTH study hospitals formed the baseline against which to evaluate any changes in documentation resulting from the presence of researchers in the L\&D ward [18].

\section{Aim}

This study aimed to assess the availability, quality, and utility of routine data in labour ward registers in five hospitals for 1 year before EN-BIRTH data collection. 
Every Newborn-Birth Indicators Research Tracking in Hospitals (EN-BIRTH) study [6]

- The Every Newborn Measurement Improvement Roadmap aims to increase the evidence base to inform selection and use of Maternal and Newborn Health indicators in national Health Management Information Systems e.g. District Health Information System (DHIS2).

- Ten core ENAP indicators were prioritised for national and global tracking, including those to measure impact, coverage, and input. Whilst the clarity of these indicator definitions vary, the availability and quality of data is limited for all ENAP core indicators [15-17].

- The EN-BIRTH study aims to test validity of selected newborn and maternal health intervention indicators (coverage/ quality aspects and/or safety) in hospitals.

- The study includes the direct clinical observation of $>20,000$ births in five Comprehensive Emergency Obstetric and Neonatal Care (CEmONC) public hospitals in Bangladesh, Nepal and Tanzania (Annex, Table 1).

- Observation/ verification data as gold standards will be compared to women's report at exit survey and to routine hospital register data [6].

Fig. 1 Summary of the EN-BIRTH study [6, 15-17]

\section{Objectives}

To evaluate routine hospital labour ward registers for 21 selected maternal and newborn data elements (Annex, Table 2):

1. Data availability: measure completeness in relation to register design.

2. Data quality: assess implausibility, internal consistency, and birthweight heaping.

3. Data utility: cross-tabulate and transform available count data to coverage/impact indicators.

\section{Methods}

\section{Study settings}

The five EN-BIRTH study sites are public hospitals in high burden Sub-Saharan African and South Asian LMIC settings and implementing the selected $\mathrm{MNH}$ interventions. Two hospitals in Bangladesh (BD) - Maternal and Child Health Training Institute (MCHTI) Azimpur, and Kushtia District Hospital; one in Nepal (NP) - Pokhara Academy of Health Sciences; and two in Tanzania (TZ) - Temeke Regional Hospital and Muhimbili National Hospital (Annex, Table 1) [6].

\section{Data collection}

Data elements/ count data required to calculate selected priority global $\mathrm{MNH}$ indicators were identified $(n=21)$ (Annex, Table 2). The data elements were extracted from routine hospital labour ward registers by trained researchers. In Bangladesh, for Caesarean section births, additional data from routine "Operation Registers" were extracted and included in the dataset. All data were extracted at the end of the 12 month study period, prior to EN-BIRTH observational data collection; in Tanzania and Bangladesh, 1st January 2016 - 31st December 2016, and in Nepal 1st April 2016 - 31st March 2017.
Data were extracted for all births in Bangladesh and Nepal, and a $20 \%$ simple random monthly sample in Tanzania, due to the high case volume. Data were directly entered into customized databases in Tanzania and Nepal and into Microsoft Excel (Version 2007) from register photographs in Bangladesh.

\section{Data analysis}

Data were analyzed in Stata 15 (StataCorp, 2017, College Station, TX).

The following data analysis methods were applied for each study objective (Table 1 ):

\section{Objective 1: availability of labour ward register data elements}

Availability of data elements: mapped across the five hospital registers by classifying the register design into one of three categories:

Specific column allotted for data element e.g. Column title: "Uterotonic for third stage of labour", documentation requires "Yes" or "No".

Non-specific column allotted for data element e.g. Column title: "Drugs given”. Uterotonic drugs are documented alongside other drugs e.g. analgesics, antibiotics etc.

No column allotted for the data element in the routine register (but may be recorded elsewhere e.g. patient case notes).

Completeness of data element recording: the percentage of total births recorded in the register with data recorded for the data element (Table 1). Whilst data completeness is often considered a data quality dimension, for the purpose of this study, we consider it separately [20]. 
Table 1 Terms and definitions of data availability, quality and utility assessed by study objectives. EN-BIRTH Baseline Register Analysis

\begin{tabular}{|c|c|c|}
\hline Study Objective & Term & Definition \\
\hline \multirow[t]{2}{*}{ Objective 1: Data Availability } & Availability & $\begin{array}{l}\text { A measure of whether the specific data element is recorded in the register in relation to } \\
\text { register design }[8,19]\end{array}$ \\
\hline & Completeness & $\begin{array}{l}\text { A measure of the proportion of entries in the register that had any data recorded for the } \\
\text { specified data element for: } \\
\text { Numerator - women or babies for whom intervention received/not received or health } \\
\text { outcome of interest recorded } \\
\text { Denominator - mothers delivered or babies born [20]. }\end{array}$ \\
\hline \multirow[t]{3}{*}{ Objective 2: Data Quality } & Implausibility & A measure of whether individual data are outside pre-defined ranges of biological credibility. \\
\hline & Heaping & $\begin{array}{l}\text { A measure of the proportion of values falling on specific values (e.g. for birthweight on } \\
2000 \mathrm{~g} \text { or } 2500 \mathrm{~g} \text { ) or rounded (i.e. ending in " } 00^{\prime \prime} \text { or " } 50^{\prime \prime} \text { ). }\end{array}$ \\
\hline & Internal consistency & $\begin{array}{l}\text { A measure of whether the observed relationship between related data elements is as } \\
\text { expected }[20,21] .\end{array}$ \\
\hline \multirow[t]{3}{*}{ Objective 3: Data Utilization } & Utility & $\begin{array}{l}\text { The transformation of count data into indicators by using them as numerators and } \\
\text { denominators or cross-tabulation. }\end{array}$ \\
\hline & Coverage & $\begin{array}{l}\text { Number of individuals receiving an intervention or service (numerator), from } \\
\text { among the hospital population in need of the intervention or service (denominator) [6]. }\end{array}$ \\
\hline & Impact & $\begin{array}{l}\text { A measure of the extent to which health status of the facility target population } \\
\text { is being achieved (e.g. maternal and newborn mortality); used for global tracking [22] }\end{array}$ \\
\hline
\end{tabular}

\section{Objective 2: quality of labour ward register data}

Three facets of data quality were assessed for a subset of data elements:

Implausibility: The proportion of extreme or unlikely values were calculated for three data elements: birthweight $(<350 \mathrm{~g}$ or $>6000 \mathrm{~g})$, gestational age $(<20$ weeks or $>44$ weeks), and women's age ( $<10$ years or $>49$ years).

Birthweight heaping and rounding were assessed in three ways. First, the proportion of birthweights rounded to $100 \mathrm{~g}$ (ending " 00 ") or $50 \mathrm{~g}$ (ending " 50 ") was calculated.

Second, rounded weight values (e.g. $2500 \mathrm{~g}$ ) were calculated as a proportion of all weights within the adjacent $250 \mathrm{~g}$ brackets (e.g. 2250-2750g). Third, the heaping ratio of the rounded weight value (e.g. $2500 \mathrm{~g}$ ) relative to the number of weights within the adjacent $250 \mathrm{~g}$ brackets, excluding the rounded value (e.g. 2250-2499 plus 2501-2749g) was calculated.

Internal consistency of data elements with expected associations were examined by cross tabulation [23]: birth outcome and breastfeeding and [1] baby outcome at discharge [20, 24].

\section{Objective 3: utility}

To explore potential use of available MNH data elements, indicators (coverage, impact, and others of programmatic relevance) (Annex Table 3) were calculated with $95 \%$ confidence intervals $(95 \% \mathrm{CI})$ using the register count data as numerators and denominators (Annex Table 4). For indicators using live births as the denominator, our calculations include only recorded live births in both numerator and denominator. Birth outcomes were further disaggregated by birthweight [6]. The effect of birthweight heaping on the Low Birth Weight (LBW) rate was explored by reallocating $50 \%$ of the birthweights recorded as exactly $2500 \mathrm{~g}$ to the LBW $(<2500 \mathrm{~g})$ category.

\section{Ethical approval}

Institutional review boards in all sites, and at the London School of Hygiene and Tropical Medicine granted ethical approval and administrative data sharing agreements were in place.

\section{Results}

Objective 1: availability of data

Data were extracted for 20,075 babies in total, 8544 in Nepal, 7111 in Bangladesh, and 4420 in Tanzania (Table 2). Across the five hospitals, 396 babies were either twins or triplets.

The labour ward registers were named: "Delivery Register" in Azimpur BD which differed from "Delivery Register" in Kushtia, BD. Both Bangladesh hospitals used "Operation Registers" for Caesarean births (Table 2). "Obstetric Register" is the national standardized register in Pokhara NP. Both Tanzanian hospitals use the national standardized HMIS labour ward register and additional data elements are captured in Muhimbili within a informal perinatal register known locally as "Midwifery Book".

The labour ward register designs are summarized in Fig. 2, shaded in black if the data element is not captured. Labour ward registers contained ten of 21 data elements in Azimpur BD, 11 in Kushtia BD, 15 in Temeke TZ, 17 in Muhimbili TZ, and 12 in Pokhara NP (Table 2). 
Table 2 Availability of data in labour ward/ operation theatre registers in five EN-BIRTH study hospitals at baseline, total births recorded $n=20,075$

\begin{tabular}{|c|c|c|c|c|c|c|c|c|}
\hline \multirow[b]{3}{*}{ Register Name } & \multicolumn{4}{|l|}{ Bangladesh } & \multirow{3}{*}{$\begin{array}{l}\text { Nepal } \\
\text { Pokhara } \\
\text { Regional } \\
\text { Obstetric } \\
\text { Register }\end{array}$} & \multicolumn{2}{|l|}{ Tanzania } & \multirow[t]{3}{*}{ Total } \\
\hline & \multicolumn{2}{|c|}{ Azimpur Tertiary } & \multicolumn{2}{|l|}{ Kushtia District } & & Temeke & Muhimbili National & \\
\hline & $\begin{array}{l}\text { Labour Ward } \\
\text { Register }\end{array}$ & $\begin{array}{l}\text { Operation } \\
\text { Register }\end{array}$ & $\begin{array}{l}\text { Labour Ward } \\
\text { Register }\end{array}$ & $\begin{array}{l}\text { Operation } \\
\text { Register }\end{array}$ & & $\begin{array}{l}\text { HMIS Labour } \\
\text { Ward Register }\end{array}$ & $\begin{array}{l}\text { HMIS Labour Ward Register } \\
\text { \& Midwifery Book }\end{array}$ & \\
\hline $\begin{array}{l}\text { Total number of babies } \\
\text { extracted in register }\end{array}$ & 1415 & 3253 & 1742 & 701 & 8544 & 2560 & 1860 & 20,075 \\
\hline $\begin{array}{l}\text { Babies of multiple births } \\
\text { (twins, triplets) }\end{array}$ & 26 & 60 & 93 & 6 & 76 & 121 & 14 & 396 \\
\hline $\begin{array}{l}\text { Total data elements in } \\
\text { register }\end{array}$ & 18 & 21 & 19 & 21 & 31 & 43 & 45 & \\
\hline $\begin{array}{l}\text { Total data elements of } \\
21 \text { requested }\end{array}$ & 10 & & 11 & & 12 & 15 & 17 & \\
\hline
\end{tabular}

Across the five hospital registers, these 21 data elements were recorded in 65 separate columns, of which 61 columns were "specific" for the data element and four columns were "non-specific". High completeness (>80\%) was found for $85.2 \%$ of the 61 specific columns compared to $25.0 \%$ of the four non-specific colums.

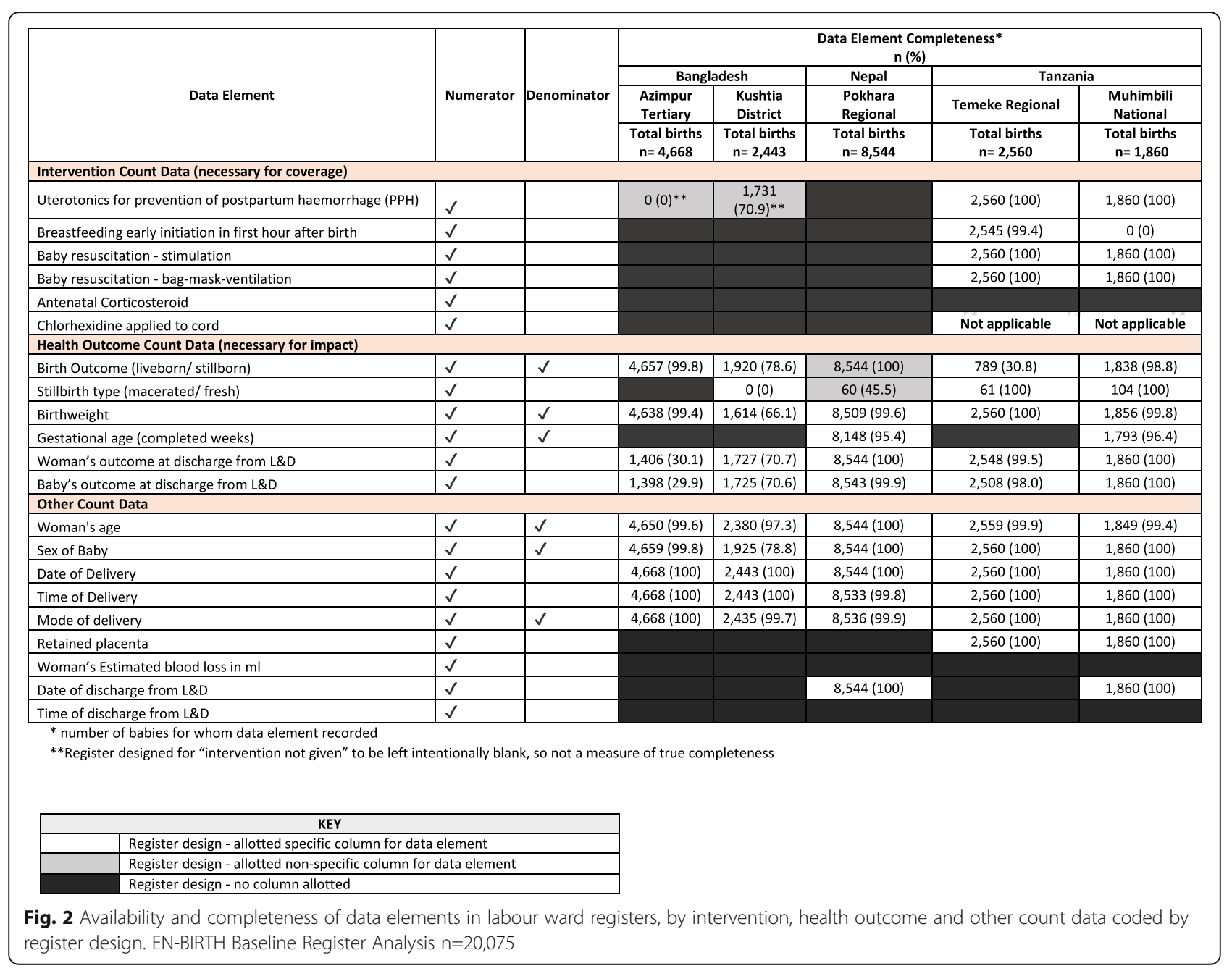




\section{Availability of intervention count data}

Uterotonics for prevention of postpartum haemorrhage $(\mathrm{PPH})$ was not captured in the register in Pokhara NP. In both the Bangladesh hospital registers uterotonics were recorded in a non-specific column "medicine given", left blank for "not given", so true completeness could not be calculated. The Tanzanian register had a specific column headed "Oxytocin, Ergometrine, or Misoprostol" and completeness was $100 \%$ in both Muhimbili and Temeke TZ (Fig. 2).

Immediate breastfeeding was not captured in either Bangladesh or Nepal registers. The Temeke TZ register had $99.4 \%$ completeness, but the same data element in Muhimbili TZ was not completed.

Newborn resuscitation data [25] were also only recorded in the Tanzanian registers, within a specific column "Helping Babies Breathe" coded: "1" suction, "2" stimulation, "3" bag-mask-ventilation and "no" for no resuscitation. Completeness in both hospitals was $100 \%$.

\section{Availability of health outcome data}

The baby's outcome at birth, live birth or stillborn, was documented in a non-specific column in Pokhara and a specific column in the other four hospitals.
Completeness of recording was $30.8 \%$ in Temeke $\mathrm{TZ}$, $78.6 \%$ in Kushtia BD and above $98.0 \%$, for the remaining hospitals (Fig. 2).

Data elements for stillbirth (SB) timing (antepartum/ intrapartum) were not available in any register and proxy measures (fresh/macerated) were allotted a specific column in Kushtia BD (completeness 0\%) and both Tanzanian hospitals (completeness 100\%) and a non-specific column in Pokhara NP (completeness 45.5\%) (Fig. 2).

Birthweight was documented in a specific column in all five registers, completeness was $>99 \%$ in four hospitals and $66.1 \%$ in Kushtia BD. Stratifying birthweight completeness by outcome showed that in Bangladesh stillbirths were much less complete, $50.0 \%$ compared to $100 \%$ for live births in Azimpur BD and 26.3\% compared to $87.8 \%$ for live births in Kushtia BD (Fig. 3). Gestational age was allotted a specific column only in Pokhara NP and in the additional perinatal register in Muhimbili TZ, completeness was $>95 \%$ in both. Women's and baby's condition at discharge from the L\&D ward had specific columns in all registers, completeness was $<80 \%$ in Azimpur BD and Kushtia BD and $>99.5 \%$ in Muhimbili and Temeke TZ and Pokhara NP (Fig. 2).

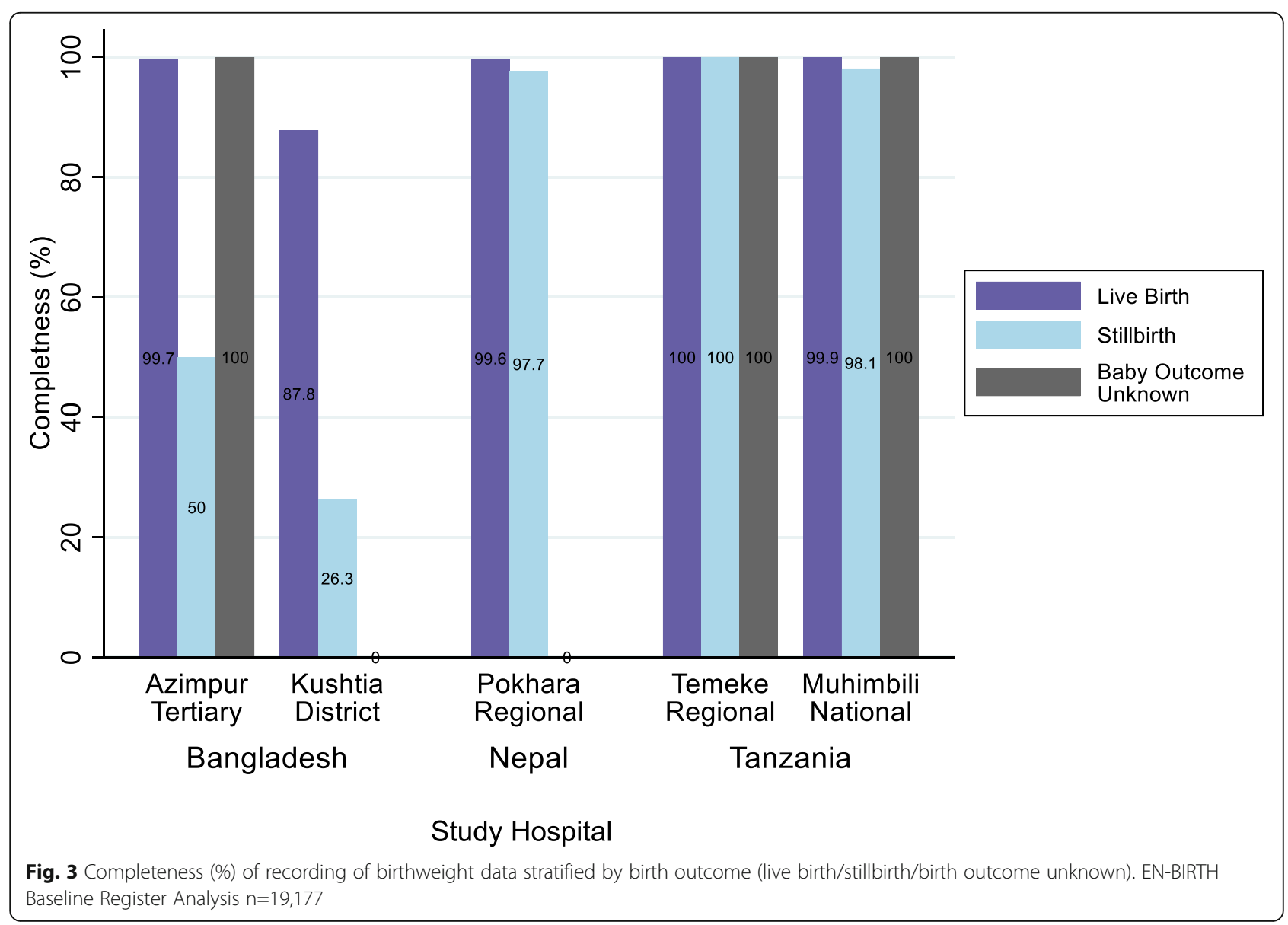




\section{Availability of other count data}

All five labour ward registers, had specific columns and $>95 \%$ completeness for: woman's age, date and time of birth, and mode of birth (Fig. 2). Baby's sex was $>95 \%$ complete in all registers except Kushtia BD, 78.8\%.

Antenatal corticosteroids, chlorhexidine application to cord (implemented in BD and NP), and time of discharge from L\&D ward were not allotted columns in any register. Date of discharge from L\&D ward was only allotted a specific column in Pokhara NP and Muhimbili TZ, 100\% complete (Fig. 2).

\section{Objective 2: quality of data Implausibility}

The proportion of implausible values was low across hospitals - for birthweight $0-1.2 \%$, for gestational age $0-0.2 \%$, and woman's age $0-0.2 \%$.

\section{Heaping}

Birthweight data were heaped in all five hospitals, in four registers more than $74 \%$ of weights were rounded to the nearest 100g (Fig. 4, Annex, Table 5). The heaping ratio was highest at 2.00 in Kushtia for 3000 g, i.e. twice as many babies were recorded as exactly $3000 \mathrm{~g}$ than at any other weight within the two adjacent $250 \mathrm{~g}$ brackets (2750-2999 and 3000-3249g) (Annex, Table 5). For the critical 2500g LBW cut-off weight, among all babies with a birthweight within range 2250-2749g, the babies with birthweight recorded as exactly $2500 \mathrm{~g}$ was very high; $60.7 \%$ in Kushtia BD, $43.5 \%$ in Pokhara NP, $42.0 \%$ in Temeke TZ, $19.5 \%$ in Azimpur BD and 18.9\% in Muhimbili TZ (Annex, Table 5).

\section{Internal consistency}

Babies with birth outcome "stillbirth" should also be recorded "died" for baby outcome at L\&D ward discharge. In Bangladesh, the non-specific discharge term "unwell" was recorded for $96.2 \%$ stillbirths $(n=25)$ in Azimpur and $94.6 \%(n=106)$ in Kushtia. The discharge term "alive" or "well" was used for $5.4 \%(n=6)$ in Kushtia BD, $16.3 \%(n=17)$ in Muhimbili TZ and 6.6\% $(n=4)$ in Temeke TZ. Stillbirths recorded as having been breastfed were $11.5 \%(n=7)$ in Temeke TZ.

\section{Objective 3: utilization of data \\ Intervention coverage indicators}

Coverage indicators calculated from the available register count data are shown in Table 3. Uterotonics coverage to prevent PPH ranged from $19.5 \%$ of live births in Temeke TZ to $89.1 \%$ of live births in Kushtia BD.

The neonatal resuscitation coverage true denominator is "babies in need of resuscitation", and as this was not available in these routine registers, a surrogate of total births (live births plus stillbirths) was used. Bag-mask ventilation $(\mathrm{BMV})$ was received by $4.1 \%(n=105)$ of total births in Temeke TZ (Table 3), among these 25.7\% ( $n=$ 27) were live births, $1.9 \%(\mathrm{n}=2)$ were fresh stillbirths, and $72.4 \%(n=74)$ had birth outcome missing. Among babies receiving BMV in Temeke TZ only $24.8 \%(n=26)$ were recorded to have also received stimulation.

\section{Impact indicators}

The facility stillbirth rate (SBR) was lowest at 7.4 in Azimpur BD and highest at 55.9 in Muhimbili TZ per 1000 total births, Table 3. The fresh SBR ranged from 2.2 in Pokhara NP to 18.9 in Muhimbili TZ per 1000 total births.

Low Birth Weight (LBW) prevalence, ranged from $10.3 \%$ in Temeke TZ to $22.6 \%$ in Muhimbili TZ, Table 3. The adjusted LBW rate (after re-allocating $50 \%$ of babies with a recorded birthweight of exactly $2500 \mathrm{~g}$ to the LBW category) increased the LBW prevalence by $1.7 \%$ in Muhimbili TZ and by 7.2\% in Kushtia BD (Table 4).

Cross-tabulating categorical birthweight with outcome (live birth/ fresh stillbirth/ macerated stillbirth) showed $62.4 \%(n=212)$ of total stillbirths and $49.3 \%(n=41)$ of fresh stillbirths were categorised LBW compared to $13.1 \%(n=2225)$ of live births (Table 5).

The preterm birth rate (number of babies < 37 weeks per 100 live births) was $4.5 \%$ in Pokhara NP and 32.5\% in Muhimbili TZ.

Maternal deaths were recorded in Pokhara NP $(n=3)$, Muhimbili TZ $(n=1)$, and Temeke TZ $(n=5)$, with none in Azimpur BD or Kushtia BD. Thus facility Maternal mortality ratio (MMR) before discharge from L\&D ward ranged from zero in both Bangladesh hospitals to 137.4 per 100,000 live births in Temeke TZ (Table 3). The neonatal mortality rate (NMR) before discharge from L\&D ward ranged from zero in Azimpur BD and Kushtia BD to 7.5 per 1000 live births in Muhimbili TZ.

\section{Other indicators of programmatic relevance}

The proportion of hospital births to adolescents (11-19 years) ranged from $4.8 \%$ in Muhimbili $\mathrm{TZ}$ to $18.6 \%$ in Azimpur BD. Ratio of male:female babies was highest in Pokhara NP at 118:100, Table 3.

Caesarean section rate, using a live birth denominator [26, 27], was $43.4 \%$, ranging from $10.4 \%$ in Kushtia to $70.2 \%$ in Azimpur BD, Table 3. As 69 stillbirths (20.2\% of total stillbirths) were also delivered by Caesarean, if these were included in the denominator [27], the Caesarean rate would decrease overall to $37.3 \%$.

\section{Discussion}

This is the largest multi-country study we are aware of in LMICs to assess labour ward register data availability, 

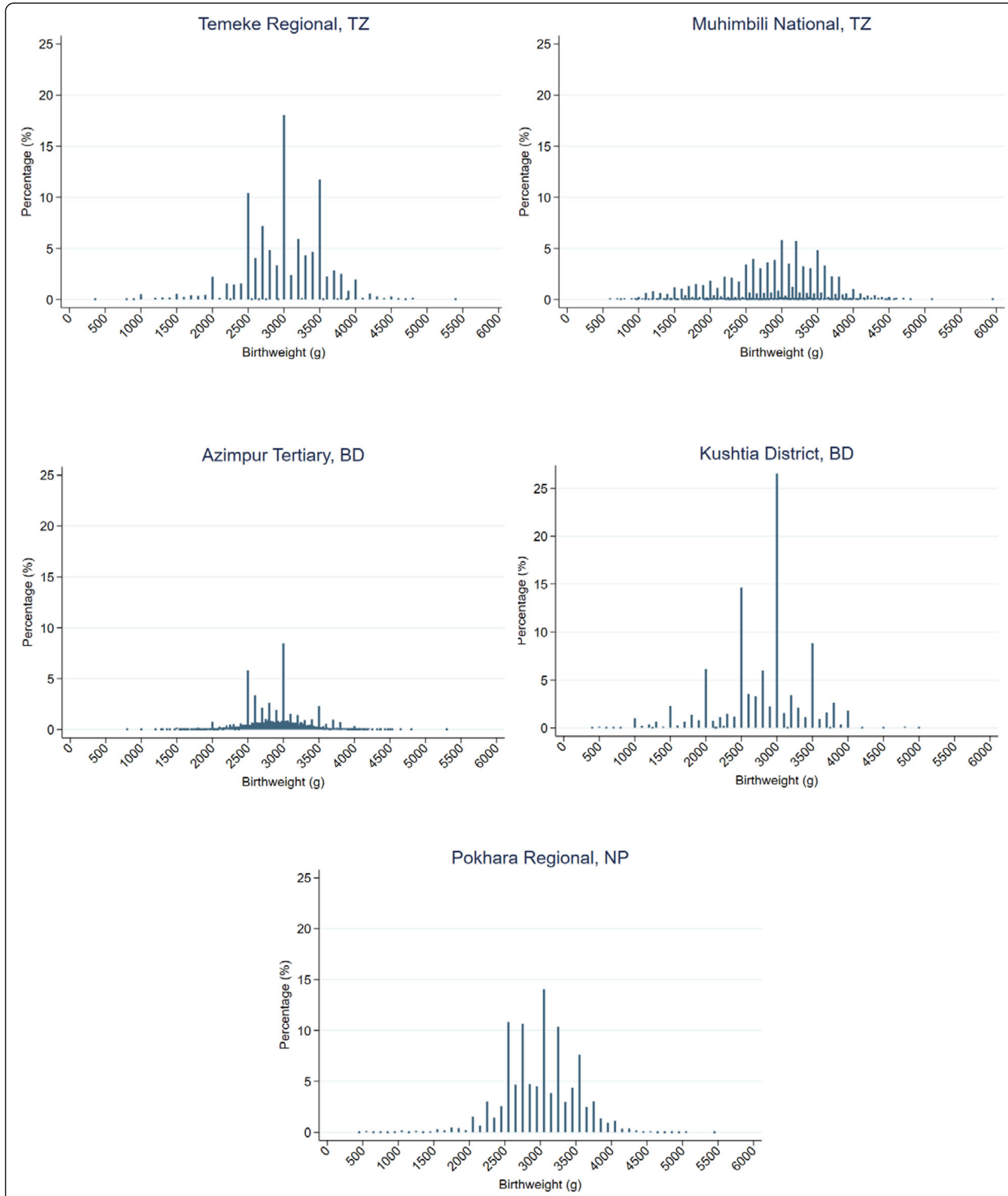

Fig. 4 Distribution of plausible birthweights recorded in each of the five EN-BIRTH study hospital labour ward registers. EN-BIRTH Baseline Register Analysis, $\mathrm{n}=19,140$ 
Table 3 Examples of data utilization - transformation of count data into indicators - EN-BIRTH registers baseline analysis $n=20,075$

\begin{tabular}{|c|c|c|c|c|c|c|}
\hline \multirow{7}{*}{$\begin{array}{l}\text { Indicator } \\
\text { Type }\end{array}$} & & \multicolumn{5}{|c|}{ Hospitals } \\
\hline & & \multicolumn{2}{|c|}{ Bangladesh } & \multirow{2}{*}{$\begin{array}{c}\text { Nepal } \\
\text { Pokhara Regional }\end{array}$} & \multicolumn{2}{|c|}{ Tanzania } \\
\hline & & Azimpur Tertiary & Kushtia District & & Temeke Regional & Muhimbili National \\
\hline & Denominator: Recorded Total Births & 4,668 & 2,443 & 8,544 & 2,560 & 1,860 \\
\hline & Denominator: Recorded Live births & 4,623 & 1,802 & 8,412 & 728 & 1,734 \\
\hline & Recorded Stillbirths & 34 & 11 & 132 & 61 & 104 \\
\hline & $\begin{array}{r}\text { Recorded birth outcome missing (babies excluded from live birth } \\
\text { denominator) }\end{array}$ & 45 & 641 & 132 & 1832 & 126 \\
\hline & \multicolumn{6}{|l|}{ Indicator } \\
\hline \multirow{4}{*}{ Coverage } & $\begin{array}{l}\text { Women receiving uterotonics for the prevention of PPH during the third } \\
\text { stage of labour/ live births } \%(95 \% \mathrm{Cl})\end{array}$ & 0 & $89.1(87.5,90.4)^{*}$ & & $19.5(16.8,22.6)^{*}$ & $34.3(32.1,36.6)^{*}$ \\
\hline & Babies breastfeeding initiated/live births \% (95\% Cl) & & & & $84.6(81.7,87.2)^{*}$ & 0 \\
\hline & Babies receiving stimulation for resuscitation/total births $\%(95 \% \mathrm{Cl})$ & & & & $3.4(2.3,5.0)$ & $0.4(0.2,0.8)$ \\
\hline & Babies receiving BMV for resuscitation/total births \% (95\% Cl) & & & & $4.1(2.6,5.4)$ & 0 \\
\hline \multirow{8}{*}{ Impact } & Stillbirth rate / 1,000 total births $(95 \% \mathrm{Cl})$ & $7.4(5.3,10.3)$ & $47.6(39.8,56.9)$ & $15.4(13.0,18.3)$ & $23.8(18.6,30.5)$ & $55.9(46.3,67.3)$ \\
\hline & Fresh stillbirth rate / 1,000 total births $(95 \% \mathrm{Cl})$ & & 0 & $2.2(1.4,3.5)$ & $10.9(7.6,15.8)$ & $18.9(14.4,27.3)$ \\
\hline & Low Birth Weight rate $(<2500 \mathrm{~g}) / 100$ live births $(95 \% \mathrm{Cl})$ & $12.6(11.6,13.6)^{*}$ & $18.5(16.7,20.5)^{*}$ & $10.5(9.8,11.2)^{*}$ & $10.3(8.2,12.7)^{*}$ & $22.6(20.7,24.6)^{*}$ \\
\hline & Preterm birth rate (<37 weeks)/100 live births $(95 \% \mathrm{Cl})$ & & & $4.5(4.1,5.0)^{*}$ & & $32.5(30.3,34.8)^{*}$ \\
\hline & Term birth rate (37-41 weeks)/ 100 live births $(95 \% \mathrm{Cl})$ & & & $87.4(86.7,88.1)^{*}$ & & $61.6(59.3,63.9)^{*}$ \\
\hline & Post-term birth rate ( 42 weeks or more) / 100 live births $(95 \% \mathrm{Cl}$ ) & & & $3.6(3.2,4.0)^{*}$ & & $2.4(1.7,3.6)^{*}$ \\
\hline & $\begin{array}{l}\text { Maternal Mortality Ratio at discharge from L\&D ward/ 100,000 live births } \\
(95 \% \mathrm{CI})\end{array}$ & 0 & 0 & $23.8(2.8,85.86)^{*}$ & $137.4(3.48,762.94)^{*}$ & $57.7(1.46,320.9)^{*}$ \\
\hline & $\begin{array}{l}\text { Neonatal Mortality Rate at discharge from L\&D ward / 1,000 live births } \\
(95 \% \mathrm{Cl})\end{array}$ & 0 & 0 & $0.8(0.3,1.7)^{*}$ & $5.49(1.50,14.01)^{*}$ & $7.5(4.0,12.7)^{*}$ \\
\hline \multirow{4}{*}{ Other } & Adolescent birth rate-facility $(11-19$ years) $/ 100$ total births $(95 \% \mathrm{Cl})$ & $18.6(17.5,19.7)$ & $7.5(6.6,8.7)$ & $13.3(12.6,14.1)$ & $12(14.8,17.7)$ & $4.8(4.1,6.2)$ \\
\hline & Neonatal Sex Ratio (\# Males per 100 Females) & 107 & 102 & 118 & 100 & 106 \\
\hline & Caesarean section Rate/ 100 live births (95\% Cl) & $70.2(68.8,71.5)^{*}$ & $10.4(9.0,11.9)^{*}$ & $23.9(23.0,24.8)^{*}$ & $14.4(12.0,17.2)^{*}$ & $64.0(61.6,66.2)^{*}$ \\
\hline & Mothers with retained placenta occurred/100 total births $(95 \% \mathrm{CI})$ & & & & $0.3(0.1,0.6)$ & $0.2(0.05,0.5)$ \\
\hline
\end{tabular}

* For indicators which use live births as the denominator: calculations include only live births in the numerator given the incomplete recording of birth outcome data (denominator) in all facilities

Grey cells indicate data element required to calculate indicator not present in the Labour Ward Register

quality, and utility. Hospital registers are key tools used to collect individual data for aggregation and transmission up the HMIS data pyramid [6]. Data extracted from five CEmONC hospitals show that a large amount of data are being collected in labour ward registers. The calculation of $\mathrm{MNH}$ coverage and impact indicators require the availability of specific data elements for use as numerators and/or denominators, yet none of the labour ward registers contained all 21 selected data elements. Data for outputs, outcomes, and impact measurement were more widely available, than for intervention coverage. Only the Tanzanian registers captured most of the selected interventions and gestational age was only captured by the Nepal register and the additional register in Muhimbili TZ.

The Performance of Routine Information System Management (PRISM) framework identifies complexity and design as technical factors in routine health information systems performance [28]. The register designs were different between countries, and within country in Bangladesh. Data were captured from the additional perinatal register in Muhimbili TZ and from operation registers for babies born by Caesarean in Bangladesh, highlighting further complexity in multiple recording systems.

Whether a specific column was allotted for the data element related to completeness of recording. Across all five hospitals, a much lower proportion of non-specific columns had high levels of completeness than did specific columns (25.0\% versus $85.2 \%)$. However, there were other examples of low completeness within specific columns (e.g. 0\% SB type Kushtia BD) or high completeness within non-specific columns (e.g. 100\% birth outcome, Pokhara NP) highlighting that technical factors alone are necessary but not sufficient for data availability.

Table 4 Adjusted and unadjusted Low Birth Weight rate - EN-BIRTH register baseline analysis n=17,033

\begin{tabular}{|c|c|c|c|c|c|}
\hline & \multicolumn{2}{|l|}{ Bangladesh } & \multirow{2}{*}{$\begin{array}{l}\text { Nepal } \\
\text { Pokhara Regional }\end{array}$} & \multicolumn{2}{|l|}{ Tanzania } \\
\hline & Azimpur Tertiary & Kushtia District & & Temeke Regional & Muhimbili National \\
\hline $\begin{array}{l}\text { Unadjusted Low Birth Weight rate } \\
(<2500 \mathrm{~g}) / 100 \text { live births }(95 \% \mathrm{Cl})\end{array}$ & $12.6(11.6,13.6)$ & $18.5(16.7,20.5)$ & $10.5(9.8,11.2)$ & $10.3(8.2,12.7)$ & $22.6(20.7,24.6)$ \\
\hline $\begin{array}{l}\text { Adjusted Low Birth Weight rate } \\
(<2500 \mathrm{~g}) / 100 \text { live births }(95 \% \mathrm{Cl})\end{array}$ & $15.6(14.5,16.6)$ & $25.7(23.6,27.9)$ & $15.9(15.2,16.7)$ & $15.0(12.6,17.8)$ & $24.4(22.4,26.4)$ \\
\hline $\begin{array}{l}\text { Increase in Low Birth Weight rate } \\
(<2500 \mathrm{~g})\end{array}$ & 2.93 & 7.20 & 5.41 & 4.67 & 1.73 \\
\hline
\end{tabular}


Table 5 Birth outcomes cross-tabulated by categorical birthweight, pooled data all EN-BIRTH hospitals baseline register analysis n=17,595

\begin{tabular}{lllllll}
\hline Birth Outcome & Total Births $^{\mathbf{a}}$ & \multicolumn{4}{l}{ Categorical Birthweight $(\mathrm{g}) \mathrm{n}(\%)$} \\
\cline { 3 - 6 } & & $\leq 999 \mathrm{~g}$ & $1000-1999 \mathrm{~g}$ & $2000-2499 \mathrm{~g}$ & $2500-3999 \mathrm{~g}$ & $\geq 4000 \mathrm{~g}$ \\
\hline Total Live births (\%) & 17,033 & $27(0.2)$ & $508(3.0)$ & $1690(9.9)$ & $14,402(84.6)$ & $361(2.4)$ \\
Total Stillbirths (\%) $^{\mathbf{b}}$ & 340 & $29(8.5)$ & $125(36.8)$ & $58(17.1)$ & $119(35.0)$ & $9(2.6)$ \\
Fresh Stillbirths (\%) $^{\mathbf{c}}$ & 83 & $4(4.8)$ & $27(32.5)$ & $10(12.0)$ & $39(47.0)$ & $3(3.6)$ \\
Macerated Stillbirths (\%) $^{\mathbf{2}}$ & 139 & $11(7.9)$ & $66(47.5)$ & $24(17.3)$ & $36(25.9)$ & $2(1.4)$ \\
\hline
\end{tabular}

ababies with a recorded birth outcome and a plausible birthweight recorded $(n=17,595)$

${ }^{b}$ includes all stillbirths from all five hospitals, ${ }^{C}$ Information on fresh or macerated stillbirths presented where available (i.e. for $100 \%$ of SB in Tanzania, $45.5 \%$ of SB in Nepal and no SB in Bangladesh)

Other factors associated with data completeness included mode of birth, e.g. in Kushtia BD $97.1 \%$ of babies for whom birth outcome was missing were delivered by Caesarean. This finding is similar to previous research in Ethiopia, where a high proportion of babies not recorded in the register had required a clinical intervention [11]. Previous studies have highlighted the low value placed on stillbirths and the resultant data gaps [29-31] and similarly we found birthweight data completeness was lower for these babies in Bangladesh.

Incomplete count data affect indicator calculation results. When intervention coverage numerators are missing, rates will appear low, e.g. when only the outcome "unwell" was recorded and no maternal/ newborn deaths, the MMR, NMR at discharge from L\&D ward and SBR may be inappropriately low - zero in Azimpur $\mathrm{BD}$ and Kushtia BD during this study. When denominators such as birth outcome are missing (e.g. for $69.2 \%$ of babies in Temeke TZ and $21.4 \%$ in Kushtia BD) many indicators which use live birth as the denominator will be adversely affected. For example, coverage of breastfeeding in Temeke TZ would be $292.5 \%$ had the numerator not been restricted to include only babies in the live births denominator (i.e. exluding babies with a birth outcome unknown). Calculating coverage using a total birth denominator instead of a clinical need denominator, as we have done for neonatal resuscitation, requires benchmarked rates for meaningful tracking across hospitals.

Alternatively, data completeness may be high, but if inaccurate, coverage will be falsely low or high. For example, uterotonic coverage was apparently low in the Tanzanian registers. These data are handwritten using a Swahili abbreviation "N" for "Ndiyo" (Yes) or "H" for "Hapana" (No) which can be hard to distinguish and possibly incorrectly extracted. Numbered coding systems may be helpful when the design is simple e.g. the "Helping Babies Breathe" column in Tanzania. Blank data elements in the register can mean either "incomplete" or a true zero, as in the Bangladesh register design, which if not differentiated can introduce another source of data inaccuracy [32].
Beyond data completeness, our data quality evaluation showed variable results. Birthweight rounding and heaping were substantial across all hospitals. If a baby whose true birthweight of $2470 \mathrm{~g}$ is rounded to $2500 \mathrm{~g}$ the LBW rate will be underestimated - in our model by up to $7.2 \%$. Both analogue and digital scales were used for birthweight across the five hospitals which may contribute to rounding. Additional ENBIRTH analyses are exploring accuracy and processes of birthweight measurement [33, 34]. In these high mortality burden countries, very large variation in hospital mortality rates may suggest data quality issues; Muhimbili TZ had a stillbirth rate almost eight times higher that Azimpur BD. The EN-BIRTH mixed-methods study aims to test validity of these indicator measurements against the gold standard of observation data.

Barriers and enablers to recording in routine hospital registers are being explored in the wider EN-BIRTH study [6]. Quality of register data is affected by HMIS input determinants described by the PRISM framework [28] including technical, organisational and behavioural factors. Factors known to negatively impact routine data quality include poor use of data, lack of feedback, low management support, lack of health worker confidence, low motivation, lack of competence and low perceived utility of routine recording tasks [14, 28, 35]. Health worker training and supportive supervision regarding the importance of routine recording around the time of birth could improve data quality for all babies, especially stillbirths. Innovations to increase health worker data utilization skills could also help sustain improvements in data recording as the purpose of these activities is recognised. Previous studies have demonstrated large gains from such efforts [12-14, 35, 36].

Further research is needed to understand the effect of labour ward register design on data quality, the impact of increased reporting burden on frontline health workers, and ways to optimize the utility of register data whilst reducing duplication. Standardized and harmonized registers with inclusion of an appropriate number of selected key data elements need evaluating against 
What is already known:

- $\quad>81 \%$ births are in hospitals and labour ward registers have potential to close the gap for coverage data around the time of birth.

- Research regarding availability and quality of register data has been sparse, especially in LMIC where the majority of deaths occur.

- 5.1 million deaths of babies around the time of birth (2.5 million neonatal deaths and 2.6 million stillbirths), majority are preventable

- Global goals to reduce these deaths require quality data to track progress and drive action. What this research adds and what next:

- First large (>20,000 babies) multi-country, multi-site detailed assessment of labour ward registers for data completeness and quality.

- Large quantities of numerator and denominator count data are currently available in the labour ward registers, which could be used now.

- Impact indicators to inform programme decision making can be calculated with currently available data, notably intrapartum stillbirth rates, with cross tabulation by weight.

- Coverage indicator data currently available in some hospitals include uterotonics, breastfeeding and neonatal bag-mask-ventilation.

- Improvements in data quality is required for certain data elements e.g. birthweight heaping

- Health workers invest time in documentation in labour ward registers, yet these data are often under-used and currently not reaching their potential to address the data gap around the time of birth.

- Large scale validation studies are needed in order to have confidence in these data, the ENBIRTH study is a response to this need.

Fig. 5 Summary figure: Labour and delivery ward register data, what is already known, what the EN-BIRTH baseline register study adds and what next

registers that contain large numbers of data elements. At the five study hospitals, all documentation at the health worker/ mother and baby interface was in paper-based routine registers. As electronic platforms increase, the effect of digitization on data quality around the time of birth requires attention from the source data to the top of the data pyramid [6].

Utilizing the EN-BIRTH multi-country study hospitals, a strength of this research is the large amount of data extracted (20,075 births), providing the first in-depth and multi-country analysis of routine labour ward register data. However, EN-BIRTH study hospitals may not be entirely representative of routine recording practices in facilities at different levels of the health system nor in other LMIC settings. Some EN-BIRTH hospitals have been involved in previous research, thus routine recording may be better than typical. Conversely, staff workload in these high-volume CEmONC hospitals could reduce data quality. We were unable to assess whether all babies born on the labour ward were recorded in the register, nor the relationship between staff levels and data quality. Research in facilities at different levels of the health system is required before wider conclusions can be drawn. Furthermore, evidence of completeness and quality of register data do not necessarily correlate with accurate aggregation and reporting from the facility up the HMIS data pyramid, therefore research is required to review quality of facility-reported data used for district/national/global tracking of $\mathrm{MNH}$ indicators.

The Every Newborn strategic objective to transform measurement aims to increase availability and quality of data to use for action. Unless all births occur in hospitals, facility data will overestimate population coverage. However, as hospital births increase (globally now $81 \%$ [7]) this data source is increasingly valuable. Improving facility data quality would also benefit wider health system indicators (e.g. immunization coverage) which currently use census projection data. Whilst household surveys are useful to provide information on contact with $\mathrm{MNH}$ services at a population level in LMICs, they have been shown to be less valid for the capture of content or coverage of interventions around the time of birth, hence new strategies incorporating multiple data sources, including register data, are required [32, 37-39]. Clarity is needed on the calculation of Caesarean section rates; the current denominator recommendation is live births, but more than $10 \%$ of stillbirths in this dataset were delivered by Caesarean [26, 27]. In our study, inclusion of stillbirths in the denominator as well as the numerator increased Caesarean rate by nearly $6 \%$. We propose Caesarean rates be calculated using hospital total births and stratified for live births and stillbirths.

Findings presented here could be used now by decision makers at various levels of the health system. In the hospital for quality improvement e.g. if no fresh 
stillbirths are being resuscitated this could lead to review of guidelines, practice and/or documentation. Birthweight data were readily available in all five hospitals, so LBW rate reporting, one of WHO 100 core health indicators could be improved [40]. If the LBW rate is implausibly low, hospitals might use the same data to improve quality of birthweight measurement. Using birthweight categories and birth outcome data, we found differences between live births and stillbirths, e.g. the differential growth of stillbirths where $36.8 \%$ weighed 1000-1999 g compared to 3.0\% of live births. Our study showed that $50.6 \%$ of fresh stillbirths had a normal birthweight yet died, this metric could also be tracked to improve quality of care.

Changes in register recording practices during the ENBIRTH study will be explored [6]. Importantly, the ENBIRTH observational study will further validate indicators from labour ward register data to inform use in HMIS and areas of focus to further improve data availability and quality.

Data used for action is foundational for tracking progress towards global goals for every woman and every child to survive and thrive $[4,5]$. As data is used, data quality and overall HMIS performance improves [14, $28]$. As data quality improves, coverage and outcome indicators can more confidently be used for action to track progress and drive change.

\section{Conclusions}

This study shows that large amounts of specific $\mathrm{MNH}$ data elements are currently available in routine labour ward registers in five hospitals in Bangladesh, Nepal and Tanzania. Data quality varied when assessed for completeness and implausibility. There is potential to improve the quality of available data if HMIS utilization with feedback loops can be strengthened. By advancing routine health facility data for use, labour ward registers can contribute to much needed regular coverage and impact measurements around the time of birth (Fig. 5). To optimize care around the critical time of birth, labour ward register data offer huge potential to be improved and used.

\section{Supplementary information}

Supplementary information accompanies this paper at https://doi.org/10. 1186/s12913-020-5028-7.

Additional file 1: Table S1. Summary information on country context and five EN-BIRTH study hospitals. Table S2. MNH data elements $(n=21)$ extracted from the labour ward and OT ward register of each of five ENBIRTH hospitals. Table S3. Definitions and examples of coverage and impact indicators, including numerator and denominator. Table S4. Indicators calculated for potential data utilization from routine register numerator and denominatorlndicators calculated for potential data utilization from routine register numerator and denominator. Table S5. Heaping of birthweight data recorded labour ward/operation registers in EN-BIRTH study hospitals.

\section{Abbreviations}

ACS: Antenatal corticosteroids; BD: Bangladesh; BMV: bag-mask ventilation; CIFF: Children's Investment Fund Foundation; DHIS2: District Health Information Systems 2; EmONC: Emergency Obstetric and Newborn Care; ENAP: Every Newborn Action Plan now branded as Every Newborn; ENBIRTH: Every Newborn-Birth Indicators Research Tracking in Hospitals study; EPMM: Ending Preventable Maternal Mortality; HMIS: Health Management Information Systems; icddr, b: International Centre for Diarrheal Disease Research, Bangladesh; IHI: Ifakara Health Institute; L\&D: Labour and Delivery; LBW: Low Birth Weight; LMIC: Low and Middle Income Countries; LSHTM: London School of Hygiene and Tropical Medicine; MMR: Maternal Mortality Ratio; MNH: Maternal and Newborn Health; MUHAS: Muhimbili University of Health and Allied Sciences; NMR: Neonatal Mortality Rate; NP: Nepal; PPH: Post-partum haemorrhage; PRISM: Performance of Routine Information System Management; RHIS: Routine Health Information Systems; SB: Stillbirth; SBR: Stillbirth Rate; TZ: Tanzania; UNICEF: United Nations International Children's Emergency Fund; WHO: World Health Organization

\section{Acknowledgements}

We credit the inspiration of the late Godfrey Mbaruku. We thank the health workers who completed the registers. We thank the National Advisory Groups in Bangladesh, Nepal and Tanzania and the EN-BIRTH Expert Advisory group for their collaboration in the EN-BIRTH study. We thank collaborating colleagues in Nepal: Nisha Rana, Jagat Jeevan Ghimire and Sushil Karki and in LSHTM: Simon Cousens, Sarah G Moxon, Angela Baschieri for their input to the EN-BIRTH study. Many thanks to Claudia DaSilva, Fion Hay, Alegria Perez, Sadie Sareen, Adeline Herman, Veronica Ulaya, Mohammad Raisul Islam and Ziaul Haque Shaikh, and Bhula Rai for their administrative support.

\section{Authors' contributions}

The full EN-BIRTH study was conceptualized by JEL, who acquired the funding and led the overall design with support from $\mathrm{HR}$ including inputs from collaborating colleagues and HB, the EN-BIRTH Expert Advisory Group, and during a multi-stakeholder research design workshop. The $\mathrm{IHI}$ and MUHAS in Tanzania hosted the study implementation workshop. HR, GRGL and DB led development of data collection tools with input from each of the three country research teams (AER, TT, EJ, OB, AKC, RP, JJ, NS, DS, JS, KS, GM). GRGL, $H R$ and $D B$ led development of training materials with country coordinators (Bangladesh: TT and AER, Nepal: NR, Tanzania: NS). Data was collected by BD: SA, SBZ; NP: AP, PC, BC, RK; TZ: AW, AK, MS, CC, AS, CM, VM, JB, JK. VSG led with development of the register matrices with major inputs from LTD OB, SBZ and JS. The cleaning and analysis of data was carried out by GRGL with LTD. The manuscript was drafted with equal contributions by LTD and GRGL: with major inputs from JEL, HR, HB, DB, VSG, AER, EJ, JS, TT, OB, NS, AKC, SBZ, SA, QSR, TH, SEA, AP, ST, RP, DP, DS, JS, KS, NM, AW, APK, MRS, CC, AOS, CM, $V M, J M B, J K$. All authors reviewed and finalized the manuscript.

\section{Funding}

The Children's Investment Fund Foundation (CIFF) are the main funder of the EN-BIRTH Study and funding is administered via The London School of Hygiene and Tropical Medicine. CIFF were involved, with many other collaborative partners, in the protocol development and implementation workshops. CIFF have not been involved in data collection or analysis. The Swedish Research Council specifically funded the Nepal site through Golden Community but was not involved in study design, data collection or analysis.

Availability of data and materials

The datasets used and/or analysed during the current study are available on LSHTM Data Compass repository, https://datacompass.Ishtm.ac.uk/955/.

Ethics approval and consent to participate

This study was granted ethical approval by Institutional Review Board of London School of Hygiene And Tropical Medicine (ref: 11780), Institutional Review Board of Ifakara Health Institute, Tanzania (ref: 032-2016), Institutional Review Board of Muhimbili University of Health and Allied Sciences, Tanzania (ref: 2016-10-21/AECNol.XI/310), Institutional Review Board of National Institute for Medical Research, Tanzania (ref: NIMR/HQ/R.8a/Nol.IX/2394), Institutional Review Board of International Centre for Diarrhoeal Disease Research, Bangladesh (ref: PR-16055), Ethical Review Committee of International Centre for Diarrhoeal Disease Research, Bangladesh (ref: PR-16055) and Nepal Health Research Council (ref: 187 /2016). 


\section{Consent for publication}

Not applicable.

\section{Competing interests}

The authors declare that they have no competing interests.

\section{Author details}

'Maternal, Adolescent, Reproductive \& Child Health (MARCH) Centre, London School of Hygiene and Tropical Medicine, London, UK. ${ }^{2}$ Maternal and Child Health Division, International Centre for Diarrhoeal Disease Research, Bangladesh (icddr,b), Dhaka, Bangladesh. ${ }^{3}$ Golden Community, Lalitpur, Nepal. ${ }^{4}$ Department of Health Systems, Impact Evaluation and Policy, Ifakara Health Institute, Dar es Salaam, Tanzania. ${ }^{5}$ Department of Women's and Children's Health, Uppsala University, Uppsala, Sweden. ${ }^{6}$ Muhimbili University of Health and Allied Sciences (MUHAS), Dar es Salaam, Tanzania. Institute of Population Health Sciences, Queen Mary University of London, Mile End Road, London E1 4NS, UK. 'ifeLine Nepal, Baneshwor, Kathmandu, Nepal. ${ }^{9}$ Yagiten Pvt Ltd, Kathmandu, Nepal. ${ }^{10}$ Muhimbili National Hospital (MNH), Dar es Salaam, Tanzania. ${ }^{11}$ Temeke Regional Referral Hospital, Dar es Salaam, Tanzania.

\section{Received: 12 July 2019 Accepted: 24 February 2020}

Published online: 12 August 2020

\section{References}

1. Bhutta ZA, Das JK, Bahl R, Lawn JE, Salam RA, Paul VK, et al. Can available interventions end preventable deaths in mothers, newborn babies, and stillbirths, and at what cost? Lancet. 2014;384(9940):347-70.

2. Lawn JE, Blencowe H, Oza S, You D, Lee AC, Waiswa P, et al. Every newborn: progress, priorities, and potential beyond survival. Lancet. 2014;384(9938): 189-205.

3. Lawn JE, Cousens S, Zupan J. 4 million neonatal deaths: when? Where? Why? Lancet. 2005;365(9462):891-900.

4. United Nations. Sustainable Development Goals 2016 [28/11/2018]. Available from: https:/www.un.org/sustainabledevelopment/health/.

5. United Nations. Global strategy for Women's, Children's and Adolescents' health, 2016-2030. New York: United Nations; 2015 Available from: https:// www.who.int/life-course/partners/global-strategy/en/.

6. Day LT, Ruysen H, Gordeev VS, Gore-Langton GR, Boggs D, Cousens S, et al. "Every Newborn-BIRTH" protocol: observational study validating indicators for coverage and quality of maternal and newborn health care in Bangladesh, Nepal and Tanzania. J Glob Health. 2019;9(1):010902.

7. World Health Organization. WHO GHO and Data Portal for Global Strategy. 2019. http://apps.who.int/gho/data/node.gswcah. Accessed 7 Jan 2020.

8. Maternal Child and Survival Program. What data on maternal and newborn health do National Health Management Information Systems Include? 2018. Available from: https://www.mcsprogram.org/resource/what-data-onmaternal-and-newborn-health-do-national-health-management-informationsystems-include/.

9. Bhattacharya AA, Allen E, Umar N, Usman AU, Felix H, Audu A, et al. Monitoring childbirth care in primary health facilities: a validity study in Gombe state, northeastern Nigeria. J Glob Health. 2019;9(2):020411.

10. Chiba Y, Oguttu MA, Nakayama T. Quantitative and qualitative verification of data quality in the childbirth registers of two rural district hospitals in Western Kenya. Midwifery. 2012;28(3):329-39.

11. Duffy S, Crangle M. Delivery room logbook - fact or fiction? Trop Dr. 2009; 39(3):145-9.

12. Mphatswe W, Mate KS, Bennett B, Ngidi H, Reddy J, Barker PM, et al. Improving public health information: a data quality intervention in KwaZulu-Natal, South Africa. Bull World Health Organ. 2012;90(3):176-82.

13. Wagenaar BH, Hirschhorn LR, Henley C, Gremu A, Sindano N, Chilengi R, et al. Data-driven quality improvement in low-and middle-income country health systems: lessons from seven years of implementation experience across Mozambique, Rwanda, and Zambia. BMC Health Serv Res. 2017;17(3):830

14. Braa J, Heywood A, Sahay S. Improving quality and use of data through data-use workshops: Zanzibar, United Republic of Tanzania. Bull World Health Organ. 2012;90(5):379-84.

15. World Health Organization. Every Newborn: An action plan to end preventable deaths (ENAP) 2014.
16. Mason E, McDougall L, Lawn JE, Gupta A, Claeson M, Pillay Y, et al. From evidence to action to deliver a healthy start for the next generation. Lancet. 2014;384(9941):455-67.

17. Moxon SG, Ruysen H, Kerber KJ, Amouzou A, Fournier S, Grove J, et al Count every newborn; a measurement improvement roadmap for coverage data. BMC Pregnancy Childbirth. 2015;15(2):S8.

18. McCambridge J, Witton J, Elbourne DR. Systematic review of the Hawthorne effect: new concepts are needed to study research participation effects. J Clin Epidemiol. 2014;67(3):267-77.

19. MEASURE Evaluation. Routine data quality assessment tool - user manual. 2017. Available from: https://www.measureevaluation.org/resources/ publications/ms-17-117.

20. World Health Organization. Data quality review: a toolkit for facility data quality assessment. Module 2. Desk review of data quality. 2017.

21. Munos MK, Stanton CK, Bryce J. Improving coverage measurement for reproductive, maternal, neonatal and child health: gaps and opportunities. J Glob Health. 2017;7(1):010801.

22. World Health Organization. Child Health and Development 2014 [18/12/ 2018]. Available from: http://www.emro.who.int/child-health/research-andevaluation/indicators/All-Pages.html.

23. World Health Organization. Global Strategy for Women's, Children's and Adolescents' Health (2016-2030). 2016.

24. Munos MK, Blanc AK, Carter ED, Eisele TP, Gesuale S, Katz J, et al. Validation studies for population-based intervention coverage indicators: design, analysis, and interpretation. J Glob Health. 2018;8(2):020804.

25. American Academy of Pediatrics. Guide for Implementation of Helping Babies Breathe (HBB): Strengthening neonatal resuscitation in sustainable programs of essential newborn care, vol. 2011; 2011. Report No.

26. MEASURE Evaluation. Cesarean sections as a percent of all births [cited 2018 29/11]. Available from: https://www.measureevaluation.org/prh/rh_ indicators/womens-health/sm/cesarean-sections-as-a-percent-of-all-births.

27. World Health Organisation. Indicator Metadata Registry: Births by caesarean section (\%) [05/04/2019]. Available from: http://apps.who.int/gho/data/node. wrapper.imr?x-id=68.

28. Aqil A, Lippeveld T, Hozumi D. PRISM framework: a paradigm shift for designing, strengthening and evaluating routine health information systems. Health Policy Plan. 2009;24(3):217-28.

29. Lawn JE, Yakoob MY, Haws RA, Soomro T, Darmstadt GL, Bhutta ZA. 3.2 million stillbirths: epidemiology and overview of the evidence review. BMC Pregnancy Childbirth. 2009;9(Suppl 1):S2.

30. Lumbiganon P, Panamonta M, Laopaiboon M, Pothinam S, Patithat N. Why are Thai official perinatal and infant mortality rates so low? Int J Epidemiol. 1990;19(4):997-1000.

31. Froen JF, Gordijn SJ, Abdel-Aleem H, Bergsjo P, Betran A, Duke CW, et al. Making stillbirths count, making numbers talk - issues in data collection for stillbirths. BMC Pregnancy Childbirth. 2009;9:58.

32. Bhattacharya AA, Umar N, Audu A, Felix H, Allen E, Schellenberg JRM, et al. Quality of routine facility data for monitoring priority maternal and newborn indicators in DHIS2: a case study from Gombe state, Nigeria. PLoS One. 2019;14(1):e211265.

33. Gladstone ME, Ogillo K, Shamba D, Gore-Langton GR, Day LT et al. Opportunities to improve quality of routine Birthweight measurement - a mixed methods study in Temeke hospital, Tanzania. BMC Pregnancy \& Childbirth [in press].

34. Kong S, Day LT, Zaman SB, Peven K, Salim N, Sunny AK, et al. Birthweight: EN-BIRTH multi-country study informing measurement quality in surveys and routine systems. BMC Pregnancy \& Childbirth [in press].

35. Sæbø Jl, Mesheck Moyo C, Nielsen P. Promoting transparency and accountability with district league tables in Sierra Leone and Malawi. Health Policy Technol. 2018;7(1):35-43,

36. Wagenaar BH, Gimbel S, Hoek R, Pfeiffer J, Michel C, Manuel JL, et al. Effects of a health information system data quality intervention on concordance in Mozambique: time-series analyses from 2009-2012. Popul Health Metrics. 2015;13(1):9.

37. Seoane G, Castrillo M, O'Rourke K. A validation study of maternal self reports of obstetrical complications: implications for health surveys. Int I Gynecol Obstet. 1998;62(3):229-36.

38. Stanton CK, Rawlins B, Drake M, dos Anjos M, Cantor D, Chongo L, et al. Measuring coverage in MNCH: testing the validity of women's self-report of key maternal and newborn health interventions during the peripartum period in Mozambique. PLoS One. 2013;8(5):e60694. 
39. Liu L, Li M, Yang L, Ju L, Tan B, Walker N, et al. Measuring coverage in $\mathrm{MNCH}$ : a validation study linking population survey derived coverage to maternal, newborn, and child health care records in rural China. PLoS One. 2013:8(5):e60762.

40. Geneva: World Health Organization. 2018 Global Reference List of 100 Core Health Indicators (plus health-related SDGs). 2018.

\section{Publisher's Note}

Springer Nature remains neutral with regard to jurisdictional claims in published maps and institutional affiliations.

Ready to submit your research? Choose BMC and benefit from:

- fast, convenient online submission

- thorough peer review by experienced researchers in your field

- rapid publication on acceptance

- support for research data, including large and complex data types

- gold Open Access which fosters wider collaboration and increased citations

- maximum visibility for your research: over $100 \mathrm{M}$ website views per year

At $\mathrm{BMC}$, research is always in progress.

Learn more biomedcentral.com/submissions 